nology by the food industry and much of the scientific community include a more abundant and economical food supply, improvements in nutritional quality, improved shelf life for fresh fruits and vegetables, foods with reduced allergenicity, development of functional foods and vaccines, conversion of nonproductive toxic soils to productive arable land, and more environmentally friendly agricultural practices [Institute of Food Technologists (IFT), 2000a].

Some examples of the above include a biotech rice carrying a gene from corn that imparts a higher rate of photosynthesis, resulting in a $35 \%$ yield increase; transgenic acid-tolerant crops developed in Mexico and predicted to increase crop yields by $50 \%$ in the tropics, thus saving some rain forests; and a golden rice that was engineered to contain beta-carotene (precursor to vitamin A), which is predicted to alleviate vitamin A deficiency and related blindness in Asia (Avery, 2000).

In 1992, the FDA provided a general outline for the safety assessment of recombinant DNA biotechnology-derived food products based on risk analysis related to the characteristics of the products. In fact, the safety assessment of foods derived from biotechnology has been more stringent than for conventionally derived products, yet concerns still exist (IFT, 2000b). One concern is allergenicity. Naturally occurring proteins found in commonly allergenic foods such as peanuts, milk, and seafood can cause gastrointestinal or cutaneous symptoms or even more serious anaphylactic shock reactions. All food allergens are proteins and since genetic modifications involve the introduction of new genes into plants, hence the production of new proteins, potential new allergenicity is possible. Thus, recombinant DNA-derived foods are assessed for allergenicity, but none has been found to date. There is also concern about introduced genetic material, such as the marker genes that confer resistance to antibiotics. Studies showed that the product of the marker gene used (neomycin phospho- transferase, type II gene, NPTII) is rapidly degraded like other dietary proteins during mammalian digestion, is not toxic, and is not likely to transfer antibiotic resistance and/or reduced efficacy of antibiotics (IFT, 2000b).

This colloquium explores the use of biotechnology as it relates to harvested horticultural crops in terms of shelf life, nutrition, decay, abscission, and flavor. We have had examples like the Flavr Savr ${ }^{\mathrm{TM}}$ tomato, which was specifically engineered to reduce softening and thus extend shelf life. Although this product was not as successful as anticipated, it set an example and other genetically engineered fruits and vegetables will surely follow. New technologies are often potentially hazardous and promising at the same time. Good examples are nuclear power and agrochemicals. The benefits of these new technologies outweigh the risks, for both are used around the world. And so it is with molecular biology. For better or worse, this technology is not likely to go away, so we had best use it wisely.

\section{Literature Cited}

Anonymous. 1999. European's views of biotechnology. The Grower. September:29.

Avery, D.T. 2000. Why we need food biotechnology. Food Technol. 54(9):132. Buckner, S. A biotech perspective. The Grower. May:27-27-32.

Institute of Food Technologists. 2000a. IFT expert report on biotechnology and foods: Benefits and concerns associated with recombinant DNA biotechnology-derived foods. Food Technol. 54(10):61-80.

Institute of Food Technologists. 2000b. IFT expert report on biotechnology and foods: Human food safety evaluation for rDNA biotechnology-derived foods. Food Technol. 54(9):53-61.

Wilkinson, J.Q. 1997. Biotech plants: From lab bench to supermarket shelf. Food Technol. 51(12):37-42.

\title{
Biochemical and Genetic Determinants of Cell Wall Disassembly in Ripening Fruit: A General Model
}

\author{
Alan B. Bennett \\ Mann Laboratory, Department of Vegetable Crops, University of California, Davis, CA 95616
}

Fruit ripening is accompanied by textural changes that are derived, at least in part, from structural changes in the cell wall. These textural changes collectively contribute to fruit softening, to increased pathogen susceptibility, and ultimately to deterioration of fruit tissue. Blocking ethylene production or perception has been shown to maintain fruit firmness and to greatly extend the shelf life of fruit (Klee, 1993; Murray et al., 1993; Picton et al., 1993). However, ethylene control also retards ripening-associated biochemical processes that contribute to the ultimate quality of the fruit. Thus, there is a continuing need to dissect the molecular mechanisms that underlie fruit softening so that these processes can be regulated independently of other aspects of fruit ripening.

Structural models of the plant cell wall remain controversial but can be viewed in the simplest form as a core structure of cellulose microfibrils embedded in two coextensive networks of pectin and hemicellulose (Carpita and Gibeaut, 1993). Recent cell wall models emphasize the degree of non-covalent associations between polymers, such as the extensive hydrogen bonding between cellulose and xyloglucan that occurs in dicot primary cell walls. This cell wall matrix provides structural support to the plant body but also must respond dynamically to developmental processes that require changes in cell shape and, in some cases, cell separation (Rose and Bennett, 1999). Thus, highly regulated disassembly of cell wall components is a critical component of plant development, and one of its most dramatic

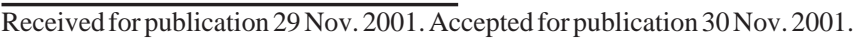

manifestations is in ripening fruit. In most cases, cellulose microfibrils are not disassembled during normal plant developmental processes, including fruit ripening. However, there is extensive evidence that both of the major matrix polymers, pectins and hemicellulose, are extensively disassembled during fruit ripening (Crookes and Grierson, 1983; Maclachlan and Brady, 1994; McCollum et al., 1989; Sakurai and Nevins, 1993). This paper reviews recent data, which suggests a general model for ripening-associated cell wall disassembly that provides experimental guidance to regulate fruit softening as a strategy to improve fruit quality.

\section{RESOLUTION OF TWO SEQUENTIAL STAGES OF CELL WALL DISASSEMBLY}

It has been recognized that fruit softening and the underlying cell wall structural changes must be complex (Fischer and Bennett, 1991). The complex patterns of cell wall disassembly may reflect cooperative biochemical actions that collectively contribute to the overall textural changes that occur in ripening fruit. Alternatively, these complex patterns of cell wall disassembly may reflect relatively distinct events that occur sequentially with each event contributing to separate and distinct aspects of fruit softening. Experiments attempting to resolve temporal events in cell wall disassembly were carried out in ripening 'Charentais' melons to assess the possibility that cell wall disassembly could be resolved into distinct sequential events (Rose et al., 1998). These experiments took advantage of the rapid ripening of climacteric 'Charentais' melon and the ability to sample fruit at specific points in 
the ripening process based on measurements of ethylene production and texture.

Cell wall fractions were isolated by sequential chemical extraction and size fractionated to assess their degree of polymerization. At the earliest ripening stage, characterized by $\approx 25 \%$ of total softening, the only cell wall fraction exhibiting any disassembly was a fraction of tightly bound hemicellulose, comprised almost exclusively of xyloglucan (Rose et al., 1998). This indicated that depolymerization of xyloglucan, which is tightly bound to the cellulose surface, was the earliest event in ripening-associated cell wall disassembly. In addition, this change in xyloglucan structure was the only cell wall change that correlated with the early stage of fruit softening. Xyloglucan disassembly has been observed in a large number of ripening fruit (Maclachlan and Brady, 1994; Tong and Gross, 1988), and characterization of ripening in 'Charentais' melon indicated that this is one of the earliest events in a sequence of cell wall disassembly.

In contrast to the early stages of fruit softening, late ripening and overripening of 'Charentais' melon fruit was characterized by progressive disassembly of the pectin network (Rose et al., 1998). Indeed, during the early stages of fruit ripening, the chelator-soluble pectins actually increased slightly in molecular size followed by a progressive decrease in average molecular mass in the final ripening and overripe stages. Analysis of molecular changes in all the pectic fractions suggested a model of pectin disassembly in 'Charentais' melon in which the loss of galactose, presumably from pectin-associated galactan side chains, contributes to the solubilization of covalently linked pectins, which are then depolymerized by the action of endopolygalacturonases in the late stages of ripening.

\section{BIOCHEMICAL AND GENETIC REGULATION OF XYLOGLUCAN DISASSEMBLY}

Mechanisms regulating xyloglucan disassembly have remained elusive in spite of the recognition of a number of enzymes capable of cleaving the $\beta$-1,4-glucan backbone of the polymer. At least two classes of enzymes can cleave the xyloglucan backbone, endo- $\beta-1,4-$ glucanase (EGase or cellulase) and xyloglucan endotransglycosylase (XET) (Rose and Bennett, 1999). In addition, expansins are a class of proteins that interact with the cellulose/hemicellulose association and may contribute to changes in this region of the cell wall, potentially increasing the accessibility of xyloglucan at this interface for enzymic attack.

EGases provide the simplest enzymic mechanism for xyloglucan cleavage and most likely play this role in a number of physiological contexts, such as cell expansion, abscission, and fruit ripening (Shani et al., 1997). However, the action of EGase alone would lead to an irreversible loss of cell wall integrity and it is likely that the action of EGases is closely coordinated with other cell wall enzymes to maintain a dynamic equilibrium between processes of cell wall assembly and disassembly. Interestingly, a membrane-bound EGase has been proposed to play a role in cell wall synthesis (Brummell et al., 1997) and a mutation in this gene in Arabidopsis appears to disrupt cell wall assembly (Nicol et al., 1998). Thus, members of the EGase gene family may be responsible both for establishing cell wall architecture as well as catalyzing its degradation.

The relation between EGase gene expression and fruit ripening has been extensively characterized, and indeed avocado EGase was the first fruit ripening-regulated cDNA clone to be identified(Christoffersen et al., 1984). It has nevertheless been difficult to firmly establish a role for ripening-regulated EGases in fruit softening. Recently, antisense suppression of expression of several EGase genes significantly suppressed tomato flower or fruit abscission but had no effect on fruit softening (Brummell et al., 1999a; Lashbrook et al., 1998). This result suggests that, while EGases may play a role in xyloglucan disassembly, single EGases do not regulate early fruit softening.

A second enzymic mechanism for xyloglucan disassembly was suggested by the discovery of a novel enzyme, xyloglucan endotransglycosylase (XET; Fry et al., 1992). XETs catalyze the cleavage and religation of xyloglucan molecules. This activity could result in progressive xyloglucan disassembly, particularly when acting in concert with EGase activity to provide low molecular size xyloglucan acceptor molecules. Ripening-regulated XETs have been identified in tomato, kiwifruit, and melon (Arrowsmith and deSilva, 1995; Schroder et al., 1998; Rose and Bennett, unpublished) and thus may play a role in xyloglucan disassembly during this developmental transition. However, it is unlikely that XETs regulate the early ripening onset of xyloglucan disassembly because XET activity is present and detectable in fruit prior to the onset of ripening (Catala et al., 2000).

Expansins are a class of proteins that have been proposed to disrupt hydrogen bonds at the cellulose/hemicellulose interface and to allow "cell wall creep" in expanding cells (Cosgrove, 1997). Expansin proteins contain a series of conserved tryptophan residues that exhibit similarity to the spacing of tryptophans in the cellulose binding domains of microbial cellulases and bind tightly to cellulose-enriched cell wall fractions (Cosgrove, 1997). In addition, expansins have been reported to "weaken" paper in the absence of detectable cellulose hydrolysis, suggesting that these proteins act by disrupting hydrogen bonds between cell wall polymers (McQueen-Mason and Cosgrove, 1994). Although expansins have been primarily characterized in relation to cell expansion, the identification of a phylogenetically divergent subclass of expansins expressed specifically in fully expanded and ripening fruit suggests that they may act in a broader physiological context (Civello et al., 1999; Rose et al., 1997).

Expression of a tomato ripening-regulated expansin gene, LeExpl, parallels the pattern of xyloglucan disassembly and early fruit softening. The LeExpl mRNA accumulates early in fruit ripening, is suppressed in transgenic fruit with low ethylene production, and is suppressed in tomato fruit carrying the rin or nor mutations that prevent normal fruit ripening and softening (Rose et al., 1997). Recently, the role of the ripening-specific Exp1 protein was investigated by suppression and overexpression of Expl in transgenic tomato plants. Fruit in which Exp1 protein accumulation was suppressed to $3 \%$ that of wild-type levels were firmer than controls throughout ripening, and fruit overexpressing high levels of recombinant Exp1 protein were much softer than controls, even in mature green fruit before ripening commenced (Brummell et al., 1999b). The softening of mature green fruit overexpressing Exp1 was correlated with the precocious and extensive depolymerization of structural hemicelluloses, whereas polyuronide depolymerization was not altered. In addition, the expression of a functional chimeric LeExpl gene in rin tomato fruit partially restores fruit softening in this ripening-impaired genetic background (Powell, Gurrieri, and Bennett, unpublished results). Taken together, these results indicate that ripening-regulated expansin proteins play a significant role in early fruit softening. The mechanism of expansin action is not clear but it seems likely that expansins act cooperatively with cell wall hydrolases, such as EGases and/or XETs, to bring about a coordinated disassembly of cell wall hemicellulose (Rose and Bennett, 1999). However, the observation that suppression of LeExpl gene expression inhibits early fruit softening indicates that expansin action is a key component of this process and may represent the primary regulator of early events in cell wall disassembly.

\section{BIOCHEMICAL AND GENETIC REGULATION OF PECTIN DISASSEMBLY}

A wide range of enzymes are known to catalyze pectin modification and disassembly. The best characterized are exo- and endopolygalacturonase, pectate lyase, pectin methylesterase, and $\beta$ galactosidase. Polygalacturonases (PGs) are the best characterized catalysts of pectin disassembly and, indeed, PGs are likely to play the major role in ripening-associated pectin depolymerization in all fruit. Although ripening melon fruit have long been known to undergo significant pectin disassembly, several reports failed to identify PG enzyme activity (Hobson, 1962; Lester \& Dunlap, 1985; McCollum et al., 1989; Ranwala et al., 1992). However, a recent examination of ripening 'Charentais' melon fruit using molecular probes identified ripening-regulated PG mRNAs that were demonstrated to encode a functional endoPG when expressed in a heterologous fungal host (Hadfield et al., 1998). Thus, while PG activity may be present at very low levels in some fruit and may be difficult to detect biochemically, it appears to be universally present in fruit that exhibit significant pectin disassembly. 
The proposal that pectin disassembly in 'Charentais' melon contributes primarily to the later stages of fruit softening and to the overripe deterioration of fruit is supported by extensive data on PG action in tomato fruit. For example, in transgenic fruit in which PG mRNA accumulation was suppressed $99 \%$ by the expression of an antisense PG transgene, depolymerization of solubilized pectins was suppressed but early fruit softening was unaffected (Brummell and Labavitch, 1997; Langley et al., 1994). In spite of the lack of effect of PG suppression on fruit softening, horticulturally important traits such as prolonged storage life in the overripe stages and enhanced viscosity of processed tomato products were observed in these low PG tomato lines (Brummell and Labavitch, 1997; Kramer et al., 1992; Schuch et al., 1991). Collectively, the results obtained with transgenic tomatoes with altered PG levels are consistent with the data from ripening 'Charentais' melon suggesting that PG-mediated pectin disassembly does not contribute to early fruit softening but does play a significant role in overripe tissue deterioration.

\section{CONCLUSIONS}

There is little doubt that ripening-regulated fruit softening is brought about by a complex series of biochemical changes that alter cell wall architecture and the rheological properties of the extracellular matrix (Fischer and Bennett, 1991). Fruit ripening-associated cell wall changes have been extensively documented but it has been difficult to assign physiological effects to specific structural changes in the cell wall. However, the availability of transgenic approaches to selectively suppress or enhance the expression of specific cell wall enzymes has recently provided the basis to critically assess the role of specific enzymes and of specific cell wall changes in the fruit softening process.

Based on the accumulated biochemical data and results from transgenic plants, we have proposed that fruit softening can be divided into at least two distinct and sequential stages. The first stage occurs in early fruit ripening and is associated with disassembly of xyloglucan polymers, particularly that fraction of xyloglucan that is bound to the cellulose surface. While a number of cell wall hydrolases may cooperate to disassemble xyloglucan at this ripening stage, expansin proteins appear to play a critical, and perhaps regulatory, role in this process. For soft fruits, such as tomatoes and berries, control of this early stage of fruit softening by regulating expansin levels has the potential to improve overall quality by allowing greater maturation prior to harvest.

The second stage of softening occurs in the overripe stage and is associated with disassembly of the pectin network. Although it is difficult to resolve the sequential stages of xyloglucan and pectin disassembly in many fruit because of the temporal overlap in these processes, the results from a detailed investigation of cell wall disassembly in 'Charentais' melon indicated that pectin disassembly occurred late in ripening and after xyloglucan disassembly (Rose et al., 1998). Interestingly, in some fruit, including melons, it has been difficult to detect PG activity in ripening fruit and it had been speculated that pectin disassembly occurred by a non-pectolytic mechanism (McCollum et al., 1989). Recent research, however, identified mRNAs in ripening melon fruit that encoded functional PG, suggesting that previous reports simply failed to detect the very low PG activity present in this fruit (Hadfield et al., 1998). Based on this result, it appears likely that PG mediates pectin disassembly in most, if not all, ripening fruit. For hard fruits, such as melon, control of the late stage of fruit softening by the regulation of PG levels may improve fruit quality by extending the shelf life of fully ripe fruit.

The generalized model of fruit softening presented here focuses on the sequential disassembly of the xyloglucan and pectin networks of the cell wall and suggests two distinct genetic strategies to separately control early or late stages of softening. It is also possible that there are interactions between these two coextensive cell wall polymeric networks and that disassembly of one network may influence the disassembly of the other. Future research should focus on using genetic strategies to assess the potential for synergistic interactions by suppression of both hemicellulose and pectin disassembly in ripening fruit.

\section{Literature Cited}

Arrowsmith, D.A. and J. de Silva. 1995. Characterization of two tomato fruitexpressed cDNAs encoding xyloglucan endo-transglycosylase. Plant Mol. Biol. 28:391-403

Brummell, D.A., and J.M. Labavitch. 1997. Effect of antisense suppression of endopolygalacturonase activity on polyuronide molecular weight in ripening tomato fruit and in fruit homogenates. Plant Physiol. 115:717-725.

Brummell, D.A., C. Catala, C.C. Lashbrook, and A.B. Bennett. 1997. A membrane-anchored E-type endo-ß-1,4-glucanase is localized on Golgi and plasma membranes of higher plants. Proc. Natl. Acad. Sci. 94:4794-4799.

Brummell D., B.D. Hall, and A.B. Bennett. 1999a. Antisense suppression of tomato endo-ß-1,4-glucanase Cel2 mRNA accumulation increases the force required to break fruit abscission zones but does not effect fruit softening. Plant Mol. Biol. 40:615-622.

Brummell, D.A., M.H. Harpster, P.M. Civello, J.M. Palys, A.B. Bennett, and P. Dunsmuir. 1999b. Modification of expansin protein abundance in tomato fruit alters softening and cell wall polymer metabolism during ripening. Plant Cell 11:2203-2216.

Carpita, N.C. and D.M. Gibeaut. 1993. Structural models of primary cell walls in flowering plants: Consistency of molecular structure with the physical properties of the walls during growth. Plant J. 3:1-30.

Catala, C., J.K.C. Rose, and A.B. Bennett. 2000. Auxin-regulated genes encoding cell wall-modifying proteins are expressed during early tomato fruit growth. Plant Physiol. 122:527-534.

Christoffersen, R.E., M.L. Tucker, and G.G. Laties. 1984. Cellulase gene expression in ripening avocado fruit: The accumulation of cellulase mRNA and protein as demonstrated by cDNA hybridization and immunodetection. Plant Mol. Biol. 3:385-391.

Civello, P.M., A. Powell, and A.B. Bennett. 1999. An expansin gene expressed in ripening strawberry. Plant Physiol. 121:1273-1279.

Cosgrove, D.J. 1997. Relaxation in a high stress environment: The molecular bases of extensible walls and cell enlargement. Plant Cell 9:1031-1041.

Crookes, P.R., and D. Grierson. 1983. Ultrastructure of tomato fruit ripening and the role of polygalacturonase isoenzymes in cell wall degradation. Plant Physiol. 72:1088-1093.

Fischer, R.L. and A.B. Bennett. 1991. Role of cell wall hydrolases in fruit ripening. Annu. Rev. Plant Physiol. \& Plant Molec. Biol. 42:675-703.

Fry, S.C., R.C. Smith, K.F. Renwick, D.J. Martin, S.K. Hodge, and K.J. Matthews. 1992. Xyloglucan endotransglycosylase, a new wall-loosening enzyme activity from plants. Biochem. J. 282:821-828.

Hadfield, K.A., J.K.C. Rose, D.S. Yaver, R.M. Berka, and A.B. Bennett. 1998. Polygalacturonase gene expression in ripe melon fruit supports a role for polygalacturonase in ripening-associated pectin disassembly. Plant Physiol. 117:363-373.

Hobson, G.E. 1962. Determination of polygalacturonase in fruits. Nature 195:804-805.

Klee, H.J. 1993. Ripening physiology of fruit from transgenic tomato (Lycopersicon esculentum) plants with reduced ethylene synthesis. Plant Physiol. 102:911-916.

Kramer, M., R. Sanders, H. Bolkan, C. Waters, R.E. Sheehy, and W.R. Hiatt. 1992. Postharvest evaluation of transgenic tomatoes with reduced levels of polygalacturonase: Processing, firmness and disease resistance. Postharvest Biol. Technol. 1:241-255.

Langley, K.R., A. Martin, R. Stenning, A.J. Murray, G.E. Hobson, W. Schuch, and C.R. Bird. 1994. Mechanical and optical assessment of the ripening of tomato fruit with reduced polygalacturonase activity. J. Sci. Food Agr. 66:547-554.

Lashbrook, C.C., J.J. Giovannoni, B.D. Hall, R.L. Fischer, and A.B. Bennett. 1998. Transgenic analysis of tomato endo- $\beta-1,4$-glucanase gene function. Role of Cel1 in floral abscission. Plant J. 13:303-310.

Lester, G.E. and J.R. Dunlap. 1985. Physiological changes during development and ripening of 'Perlita' muskmelon fruits. Sci. Hort. 26:323-331.

Maclachlan, G. and C. Brady. 1994. Endo-1,4- $\beta$-glucanase, xyloglucanase, and xyloglucan endotransglycosylase activities versus potential substrates in ripening tomatoes. Plant Physiol. 105:965-974.

McCollum, T.G., D.J. Huber, and D.J. Cantliffe. 1989. Modification of polyuronides and hemicelluloses during muskmelon fruit softening. Physiol. Plant. 76:303-308

McQueen-Mason, S.J. and D.J. Cosgrove. 1994. Disruption of hydrogen bonding between plant cell wall polymers by proteins that induce wall extension. Proc. Natl. Acad. Sci. USA 91:6574-6578.

Murray, A.J., G.E. Hobson, W. Schuch, and C.R. Bird. 1993. Reduced ethylene synthesis in EFE antisense tomatoes has differential effects on fruit ripening processes. Postharvest Biol. Technol. 2:301-313.

Nicol, F., I. His, A. Jauneau, S. Vernhettes, H. Canut, and H. Hofte. 1998. A plasma membrane-bound putative endo-1,4- $\beta-D$-glucanase is required for normal wall assembly and cell elongation in Arabidopsis. EMBO J. 17:5563-5576 
Picton, S., S.L. Barton, M. Bouzayen, A.J. Hamilton, and D. Grierson. 1993. Altered fruit ripening and leaf senescence in tomatoes expressing an antisense ethylene-forming enzyme transgene. Plant J. 3:469-481.

Ranwala, A.P., C. Suematsu, and H. Masuda. 1992. Role of $\beta$-galactosidases in the modification of cell wall components during muskmelon fruit ripening. Plant Physiol. 100:1318-1325.

Rose, J.K.C. and A.B. Bennett. 1999. Cooperative disassembly of the cellulosexyloglucan network of plant cell walls: Parallels between cell expansion and fruit ripening. Trends in Plant Sci. 4:176-183.

Rose, J.K.C., H.H. Lee, and A.B. Bennett. 1997. Expression of a divergent expansin gene is fruit-specific and ripening-regulated. Proc. Natl. Acad. Sci. USA 94:5955-5960

Rose, J.K.C., K.A, Hadfield, J.M. Labavitch, and A.B. Bennett. 1998. Temporal sequence of cell wall disassembly in rapidly ripening melon fruit. Plant Physiol. 117:345-361.
Sakurai, N. and D.J. Nevins. 1993. Changes in physical properties and cell wall polysaccharides of tomato (Lycopersicon esculentum) pericarp tissue. Physiol. Plant. 89:681-686.

Schröder, R., R.G. Atkinson, G. Langenkämper, and R.J. Redgwell. 1998 Biochemical and molecular characterisation of xyloglucan endotransglycosylase from ripe kiwifruit. Planta 204:242-251.

Schuch, W., J. Kanczler, D. Robertson, G. Hobson, G. Tucker, D. Grierson, S. Bright, and C.R. Bird. 1991. Fruit quality characteristics of transgenic tomato fruit with altered polygalacturonase activity. HortScience 26:1517-1520.

Shani, Z., M. Dekel, G. Tsabary, and O. Shoseyov. 1997. Cloning and characterization of elongation specific endo- $\beta$-1,4-glucanase (cell) from Arabidopsis thaliana. Plant Mol. Biol. 34:837-842.

Tong, C.B.S. and K.C. Gross. 1988. Glycosyl-linkage composition of tomato fruit cell wall hemicellulose fractions during ripening. Physiol. Plant. $74: 365-370$.

\title{
Manipulation of Ethylene Synthesis and Perception in Plants: The Ins and the Outs
}

\author{
Harry J. Klee \\ University of Florida, Horticultural Sciences, POB 110690, Gainesville, FL 32611 \\ David G. Clark \\ University of Florida, Environmental Horticultural, POB 110670, Gainesville, FL 32611
}

The biological effects of ethylene on plant growth and development have been documented for over a century. Ethylene profoundly influences many aspects of development, both pre- and postharvest (Abeles et al., 1992). Spoilage losses ascribed to ethylene effects are significant for both food and ornamental crops. The major agricultural losses associated with ethylene have spurred research on methodologies for control of its synthesis and action. We have been particularly interested in two physiological processes associated with high economic value: fruit ripening and flower senescence. This article addresses biotechnological approaches to control these two processes. There are multiple strategies for controlling ethylene synthesis and response. We will limit our discussion to those with which we have personal experience. Although we will not cover all of the potential target genes, the strategies outlined here apply to the other gene targets.

Fruits in which ripening is controlled by ethylene are generally referred to as climacteric. Examples include tomato, melon, mango, papaya, and banana. Our efforts have focused on tomato as a model for several reasons. The tomato is relatively easy to genetically modify via Agrobacterium tumefaciens-mediated transformation. It has a broad base of physiological, biochemical, and genetic research on which to build. It is also a highly important commercial crop, being the number one valued vegetable produced in Florida (Lucier, 2000). Partly because of its economic importance, much research has been focused on the molecular biology of tomato ethylene synthesis and perception.

Like climacteric fruits, a subset of flowers produce and senesce in response to ethylene. One of the best understood of these species is petunia. A petunia flower will produce large amounts of ethylene within hours of pollination. Exposure of flowers to ethylene induces rapid loss of turgor that leads to corolla wilting within 1 to $2 \mathrm{~d}$. Like tomato, petunia is readily transformable and has an excellent foundation of genetic, physiological, and biochemical research. All of these factors make it an excellent model system for genetic manipulation.

\section{GENES INVOLVED IN ETHYLENE BIOSYNTHESIS}

Ethylene is synthesized from the common metabolic precursor $S$ adenosylmethionine (SAM). Synthesis of ethylene is a two-step pro-

Received for publication 29 Nov. 2001. Accepted for publication 30 Nov. 2001 Florida Agricultural Experiment Station Journal Series No. R-08732. This work was funded in part by a USDA/NRI grant to H.J.K., Monsanto Company, and the Fred C. Gloeckner Foundation. cess that is highly transcriptionally regulated. The limiting step is catalyzed by ACC synthase (ACS). This enzyme converts SAM to 1aminocyclopropane-1-carboxylate (ACC). That ACC is then converted by ACC oxidase (ACO) to ethylene. In all plants examined to date, ACS is encoded by a complex multigene family (Oetiker et al., 1997; Rottmann et al., 1991). There are at least 10 tomato genes encoding different ACC synthases. These genes are highly regulated and each is induced in a different way by various developmental or environmental cues (Oetiker et al., 1997). There are two specific ACS genes that are responsible for synthesis of all of the ACS enzyme made during tomato fruit ripening. These genes are positively regulated by ethylene. This regulation explains the autocatalytic synthesis of ethylene during tomato fruit ripening; a small amount of ethylene leads to a rapid and large increase in ethylene at the onset of ripening. Synthesis of ACC seems to be the most highly regulated step in ethylene synthesis. ACO is also somewhat regulated, also being ethylene inducible, but does not appear to be limiting under normal circumstances. In the tomato fruit, one of the four genes appears to encode most of the ACO enzyme.

Researchers have used biotechnological approaches to shut off synthesis of both ACC synthase and ACC oxidase with great success (Hamilton et al., 1990; Oeller et al., 1991). In tomato, antisense ACS and ACO gene expression leads to effective shut-off of the endogenous ripening-associated genes. Using this antisense strategy, ethylene synthesis has been blocked and fruits from these plants do not ripen.

An alternative strategy to antisense shut-off of endogenous genes involves expression of a gene encoding ACC deaminase. This enzyme degrades ACC to $\alpha$-ketobutyric acid, a precursor of branched chain amino acids (Klee et al., 1991). The gene encoding ACC deaminase was originally isolated from a Pseudomonas species isolated from soil. When the gene is expressed in a plant, the enzyme competes with ACO for ACC. If enough ACC deaminase is present, the plant will accumulate far less ACC.

\section{GENES INVOLVED IN ETHYLENE PERCEPTION}

In the last several years, great progress has been made in the area of ethylene perception and signal transduction (Bleecker and Schaller, 1996). The ability to make mutants that are insensitive to ethylene and then to clone the corresponding genes has led to identification of several genes that are essential for the ethylene signal to be perceived by plants. We have focused our attention on the first gene in the 